\title{
A PERCEPÇÃO DO PATRIMÔNIO CULTURAL: SISTEMA DE GESTÃO E REPRESENTAÇÕES
}

\author{
PERCEPTION OF CULTURAL HERITAGE: \\ MANAGEMENT SYSTEM AND REPRESENTATION
}

Luiz Viva
Giulia Crippa

Resumo: O texto apresenta, em linhas gerais, a ideia central do projeto de pesquisa de doutorado em desenvolvimento no PPGCI/USP, que visa propor a uma análise crítica das informações produzidas pelo Instituto do Patrimônio Histórico e Artístico Nacional - IPHAN relativas aos bens culturais salvaguardados. O patrimônio cultural é observado na perspectiva de sua representação através dos documentos elaborados pelo órgão e sua apropriação pela sociedade, considerando o espelhamento das normativas legais de preservação em sistemas que operam de modo desarticulado, de acordo com as especificidades tipológicas dos bens salvaguardados. À pesquisa interessa também analisar os processos de patrimonialização adotados pela instituição, à luz de aspectos críticos em relação à manipulação oficial do passado.

Palavras-chave: IPHAN. Patrimônio cultural. Preservação cultural.

Abstract: The paper presents, in general lines, the central idea of the project of doctoral research in development in the PPGCI / USP, that aims to propose a critical analysis of the information produced by the National Historical and Artistic Heritage Institute (IPHAN) regarding cultural assets safeguarded. The cultural heritage is observed in the perspective of its representation through the documents elaborated by the organ and its appropriation by society, considering the mirroring of the legal norms of preservation in systems that operate in a disjointed way, according to the typology of the resources safeguarded. The research also aims to analyze the patrimonialisation processes adopted by the institution, in light of critical aspects regarding the official manipulation of the past.

Keywords: Cultural Heritage; cultural preservation; IPHAN.

\section{Introdução}

Este texto aborda, em linhas gerais, a pesquisa de doutorado em desenvolvimento no PPGCI/USP, cujo projeto parte do pressuposto de que os diferentes sistemas destinados à organização do conhecimento no âmbito do Instituto do Patrimônio Histórico e Artístico Nacional - IPHAN não permitem uma abordagem integrada do patrimônio cultural.

A premissa do trabalho parte da constatação de que as informações produzidas pelo órgão estão estruturadas em grupos temáticos desarticulados, e que tal quadro deriva de uma percepção compartimentada do patrimônio cultural, refletida nas normas e no modo como tais informações são disponibilizadas à sociedade. 
VI Seminário de Pesquisa em Ciência da Informação do PPGCI 2017

Escola de Comunicações e Artes - Universidade de São Paulo

Com isso, em que pese a necessidade da instituição em elaborar manifestações públicas de caráter abrangente, visto que o conceito de patrimônio cultural é legalmente assim reconhecido, acolhendo componentes de natureza diversa, materiais e imateriais, conforme o previsto no artigo 216 da Constituição Federal (BRASIL, 1988), observa-se, por outro lado, que a organização das informações produzidas não permite a interface entre as diferentes áreas do conhecimento vinculadas aos bens salvaguardados, situação que favorece decisões em um campo de atuação em detrimento de outros.

\section{Questões subjacentes ao patrimônio cultural salvaguardado}

Os parâmetros utilizados pelo IPHAN para normatizar os processos de patrimonialização e organizar as informações sobre os bens patrimoniais salvaguardados serão abordados sob a visão de Hjorland, onde questões históricas, sociais e políticas não podem ser deixadas de lado na análise de um campo de conhecimento específico (2008, p. 179).

Neste sentido, observa-se na contemporaneidade uma "epidemia de memória, com manipulações, que precisa ser controlada pelas sociedades midiatizadas" (HUYSSEN, 2000, p. 31), o que pode ser contraposto a colocação de Pierre Nora (1993), ao indicar que "fala-se tanto de memória porque ela não existe mais”. O que a princípio poderia ser tratado como uma oposição de ideias expõe, no entanto, outro aspecto inerente à memória: os interesses subjacentes à sua preservação na sociedade globalizada.

Assim sendo, pode-se dizer que a memória, enquanto conhecimento acumulado por um determinado grupo social, deixa de existir nesse sentido a partir do momento em que agentes estranhos àquele conhecimento inicial estabelecem critérios para a sua seleção (indicando o que deve ou não ser esquecido) e reprodução, utilizando-a conforme seus interesses políticos, econômicos e sociais, constituindo, assim, novas relações de poder através do domínio do saber (poder/saber).

Os bens patrimoniais salvaguardados, portanto, não podem ser encarados apenas como testemunhos de outrora, mas como objetos socialmente construídos, que refletem a manipulação oficial do passado através do gerenciamento do patrimônio cultural, utilizado na materialização do conceito de identidade nacional (FUNARI, 2001, p. 2) e consequente produção de significados, transmitidos pelos documentos oficiais, entendendo-se os mesmos como "qualquer indicação simbólica ou concreta, preservada ou guardada" (BUCKLAND, 1997). 
VI Seminário de Pesquisa em Ciência da Informação do PPGCI 2017

Escola de Comunicações e Artes - Universidade de São Paulo

A construção do discurso oficial pode também ser apreendida enquanto processo de produção de conhecimento, conformando uma narrativa entendida como uma sucessão de eventos que, na definição de Braudel, apesar de pertencerem à superficialidade do tempo acelerado, interessam pelo "que se revela sobre as forças que lhe são subjacentes" (cf. BURKE, 2002, p. 211).

$\mathrm{O}$ conceito de cultura, por sua vez, é inerente à organização institucional do patrimônio cultural, podendo ser entendido por um "conjunto de processos sociais de produção, circulação e consumo da significação na vida social" (CANCLINI, 2015, p. 41). Deste modo, pode-se afirmar que a cultura "permeia toda a sociedade", e o seu estudo "ressalta o domínio simbólico no centro da vida em sociedade" (HALL, 2016, p. 21).

\section{Resultados esperados}

Como resultado da pesquisa, espera-se uma análise crítica dos sistemas de informação na área do patrimônio cultural no âmbito federal, que na atualidade reproduzem as divisões administrativas formais do órgão de preservação. Além disso, os processos que viabilizam a patrimonialização dos objetos e tradições deverão ser analisados, considerando os aspectos relativos ao papel do órgão de preservação em determinar aquilo o que deve ser lembrado e o que pode ser esquecido.

Deste modo, não obstante as especificidades das áreas do conhecimento associadas a cada uma das categorias do patrimônio cultural, deve-se procurar sugerir a adoção de mecanismos que integrem, de fato, os objetos de salvaguarda de diferentes naturezas, contribuindo, assim, com políticas públicas sob uma abordagem holística cuja adoção, na prática, é limitada ou impedida por barreiras administrativas e normativas.

\section{Referências}

BRASIL. Constituição da República Federativa do Brasil. Brasília, DF: Senado Federal, 1988.

BUCKLAND, Michael Keeble. What is a "document"? Journal of the american society for information science (1986-1998), New York, v. 48, n. 9, p. 804-809, set. 1997.

BURKE, Peter. História e teoria social. São Paulo: UNESP, 2002.

CANCLINI, Néstor García. A sociedade sem relato: antropologia e estética da iminência. São Paulo: EDUSP, 2016.

FUNARI, Pedro Paulo de Abreu. Os desafios da destruição e conservação do patrimônio cultural no Brasil. Trabalhos de antropologia e etnologia, Porto, 41, 1/2, p. 23-32, 2001. 
VI Seminário de Pesquisa em Ciência da Informação do PPGCI 2017

Escola de Comunicações e Artes - Universidade de São Paulo

HALL, Stuart. A centralidade da cultura: notas sobre as revoluções culturais do nosso tempo.

Educação \& realidade, Porto alegre, v. 22, n. 2, p. 15-46, jul./dez. 2017.

HJORLAND, Birger. The Domain analysis in information science: eleven approaches:

traditional as well as innovative. Journal of the American Society for Documentation, v. 58, n. 4, p.422-462, 2002.

HUYSSEN, Andreas. Seduzidos pela memória: arquitetura, monumentos, mídia. Trad. Sérgio Alcides. Seleção de textos por Heloisa Buarque de Hollanda. Rio de Janeiro:

Aeroplano, 2000.

NORA, Pierre. Entre memória e história: a problemática dos lugares. Trad. Yara Aun Khoury. Tradução de Les lieux de mémoire. Projeto história, São Paulo, n. 10, p. 7-27, dez. 1993.

\section{Sobre o autor e a autora}

\section{Luiz Viva}

Arqueólogo e arquiteto, doutorando do PPGCI/ECA/USP.

\section{Giulia Crippa}

Professora doutora do PPGCI/ECA/USP. 